\title{
New textiles for metalurgists and welders: impregnation or fire, heat-resistant fibers
}

\section{Introduction}

The present manuscript is dedicated to the protection of individuals against various adverse factors, such as high temperatures during a longtime period, high temperatures in working environments, sudden explosion and inflammation, and laser-ionizing radiation (welding).

Taking into account a rapid increase up to $37 \%$ of accidents occurred in Russia in 2014 compared to 2013, including 26\% caused by the factors mentioned above, the creation of clothes and other textiles with protective features is becoming more essential.

The analysis of textile production for fire- and heat resistant clothing over the last 10 years (from 2002 to 2012) has shown that till 2012 mainly natural fabrics were used worldwide to create protective clothing, protective effect of which was determined by their thickness, weight and specific impregnation. Nowadays for the production of high-quality protective clothing different synthetic fibers and yarns with heightened protection factors are extensively used purely or in a mixture with various yarns, including natural ones.

New fire- and heat-resistant fibers appearing in Russia: aramid (high-performance and high-modulus) and polyacrylonitrile-oxidized, allow to create purely or in a mixture with natural fibers and fireproof impregnation qualified fabrics for work wear, which can guarantee safe working conditions for those working at severely hazardous facilities. ${ }^{1}$

The following article is devoted to research and comparative analysis of physical-mechanical, physical-chemical and fire-resistant features of fireproof fabrics developed by means of different production types:

i. Variant No1-mixture of fireproof (aramid) and natural fibers (cotton) with flameproof impregnation;

ii. Variant No2-100\% mixture of aramid and polyacrylonitrile-oxidized fibers;

iii. Variant No3-100\% mixture of different aramid fibers.

There've been examined qualities of the created fabrics and those after 5 cleanings, Figures 1-7. The analysis of physical-mechanical and hygienic features of the fabrics, created by different types, in comparison to GOST (The State Standard), has shown the exceeding of almost all indicators, both in warp and weft, excluding the indicator "Absorbability" in Variant 3 Figure 6.

Thus, the increase of tensile strength of the fabrics from variant 1 exceeds the demands of GOST twice in warp, 1, 3 times-in weft, variants 2 and 3-3times in warp, 2,5times in weft. This tendency can also be seen on the "Tearing load" indicator. The "Abrasion resistance" indicator exceeds GOST 3,7times in variant 1and in variants 2 and 3-6times.

Besides, all these features do not alter after cleaning in all variants, and they even increase on the "Abrasion resistance" indicator.

If we compare variant 1 with variants 2 and 3 , we can note that
Volume I Issue 2 - 2017

\author{
Lavrentyeva E,' Kovalchuk L² \\ 'Doctor of technical sciences, Russia \\ ${ }^{2}$ Candidate of technical sciences, Russia
}

Correspondence: Lavrentyeva E, Doctor of technical sciences, Innovative Research and Production Center for Textile and Consumer Goods Industry, OJSC, Moscow, Russian Federation, Russia,Tel+79165073539, Email unitex_@list.ru

Received: February 15, 2017 | Published: March 03, 2017

fabrics created of $100 \%$ fireproof fibers have increased their strength indicators and abrasion resistance.

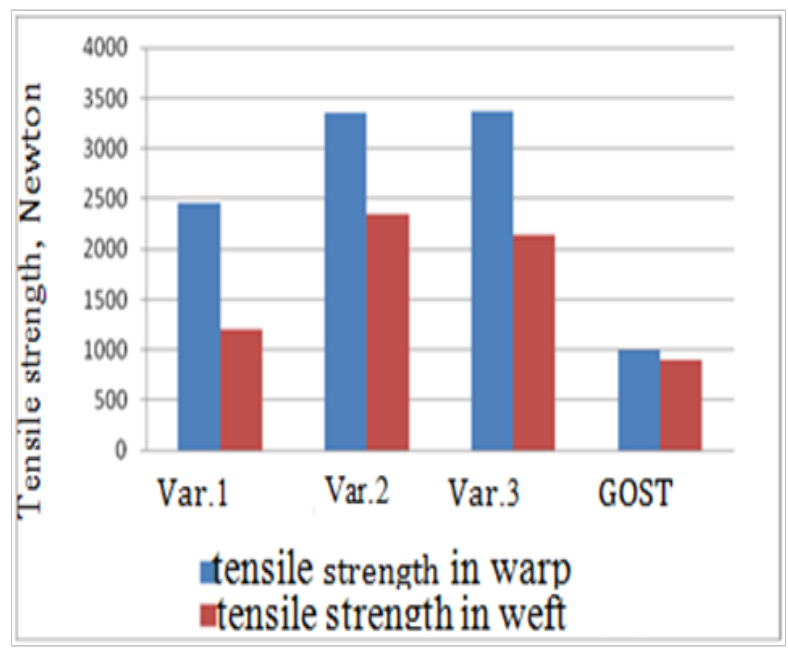

Figure I Dependence of tensile strength on the type of fabric.

Fabrics used in work wear production should also comply with applicable standards and customer quality requirements, such as breathability, absorbability and specific electric value. The recent analysis has shown that the textiles created with a mixture of natural, fire resistant fibers and impregnation can provide better hygienic properties. $^{2}$

The examination of specific protective features has shown that:

A. All the examined textiles are fire resistant, i.e. they neither burn nor smolder after placing them into the open flame for 30 seconds, which meets the GOST indicators;

B. All the examined fabrics have high oxygen index, starting from $36-44 \%$, which complies with GOST (not less than $28 \%$ ).

The examination of fire- and heat-resistance of the developed textiles illustrates the excess of these indicators in comparison to the 
demands of GOST. A high level of oxygen index is noted in all the created fabrics. Meanwhile the textiles with impregnation show a $15 \%$ higher oxygen index indicator than $100 \%$ flameproof manmade yarns. It's worth noting that variants 2 and 3 made of $100 \%$ flameproof fibers provide fire resistance 1,1-2 times higher than the textiles from variant 1 , which are made of a mixture of flameproof fibers, natural fibers and impregnation. Besides, and it's very important to notice, all the examined fabrics reduce flame resistance after 5 cleanings, and variant 1 is lower than the demands of GOST, which proves the advantage of $100 \%$ flameproof fibers in specifically harsh conditions of exploitation. ${ }^{2,3}$

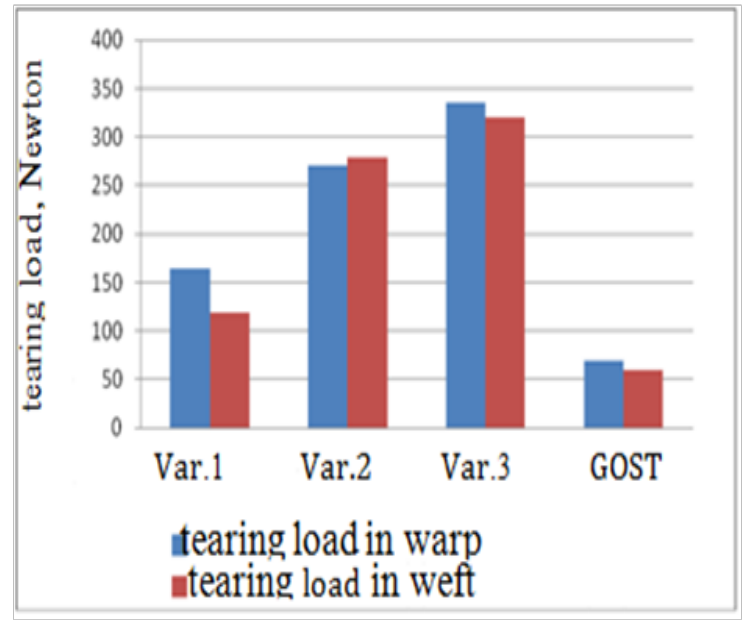

Figure 2 Dependence of tearing load on the type of fabric.

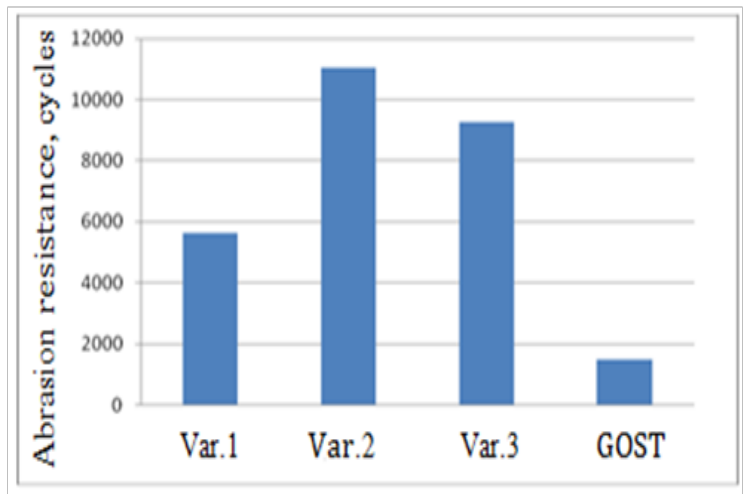

Figure 3 Abrasion resistance.

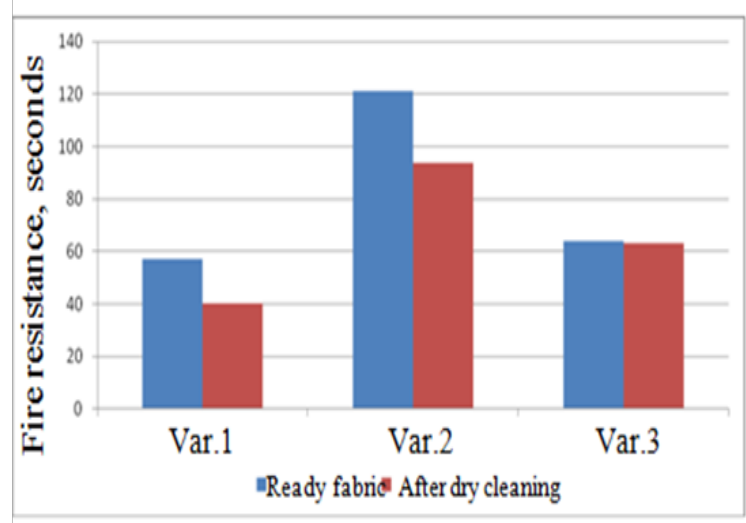

Figure 4 Fire resistance.

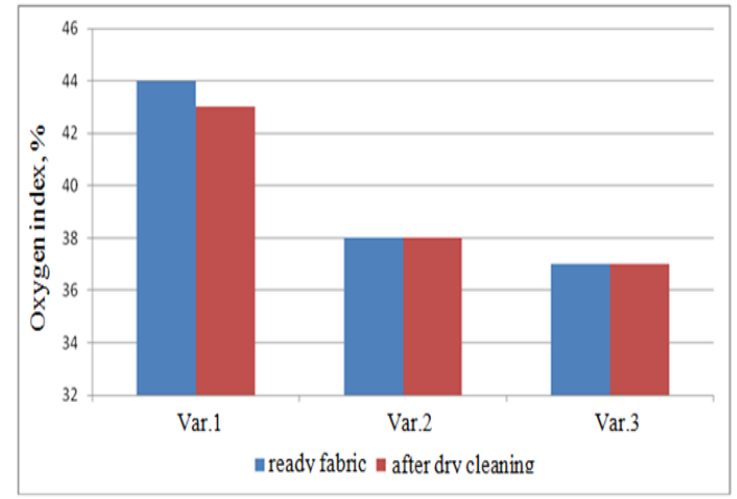

Figure 5 Oxygen index.

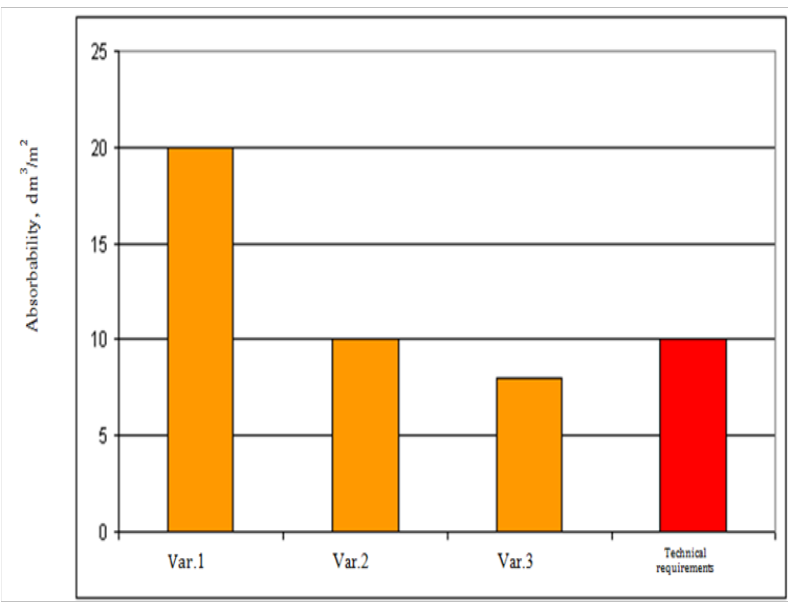

Figure 6 Dependence of absorbability on the type of fabric.

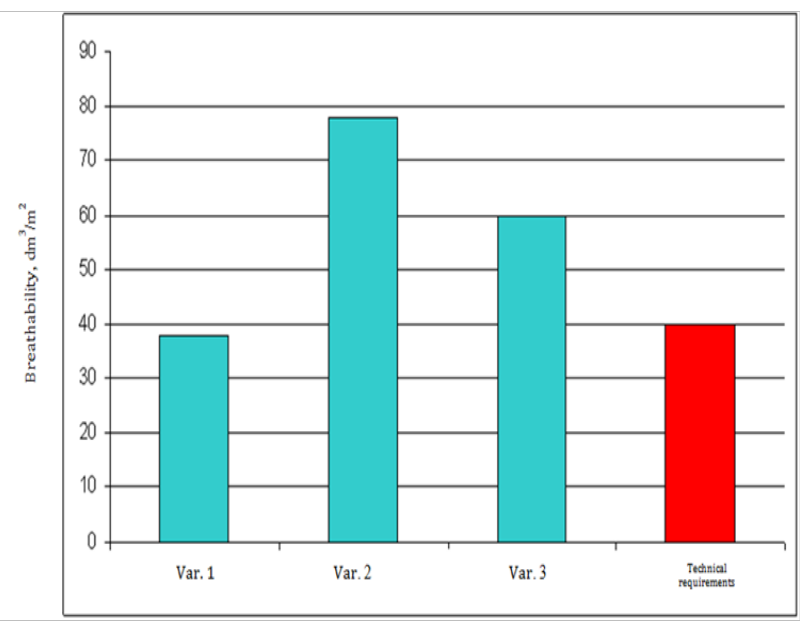

Figure 7 Dependence of breathability on the type of fabric.

\section{Conclusion}

a. In Russia there's been developed a series of flameproof textiles created of $100 \%$ flameproof chemical fibers, as well as a mixture of natural fibers, flameproof chemical fibers and flameproof impregnation with Russian chemicals.

b. All the developed fabrics provide a wide range of strength, fire-resistant and hygienic properties. 
c. Almost all of these textiles maintain their indicators after 5 cleanings and are recommended for use depending on the exploitation demands.

d. Taking into consideration that the cost of the textiles made of $100 \%$ chemical flameproof fibers is higher than of those made of a of mixture of natural fibers, flameproof chemical fibers and flameproof impregnation, the consumer has a choice in accordance with the price-quality ratio.

\section{Acknowledgments}

None.

\section{Conflict of interest}

Author declares there is no conflict of interest in publishing the article.

\section{References}

1. Fomchenkova LM. Modern Textiles for Work wear. Textile Industry. 2002.

2. GOST 12.4.105-81 Occupational standards safety system. Fabrics and materials for welder's work wear. Standards Publishing. 2002.

3. GOST 12.4.297-2013 Occupational standards safety system. Clothing for protection against high temperatures, convective heat, molten splashes of metal, contact heat, limited flame spread. Technical requirements and test methods, Standartinform. 2014. 